\title{
Words in Place: Critical Architectural Messages on the Surface of the City
}

\author{
ANGELIKI SIOLI \\ Louisiana State University
}

This paper examines an alternative approach for the teaching of architectural theory in the context of the Mexican city of Puebla. After a short description of the local context and a presentation of the course (syllabus, readings, assignments) it unpacks in detail-and through specific examples-the "Words in Place" project, elaborating on its pedagogical objectives and the opportunities it provides for the teaching of theory as a way to cultivate an ethical position.

\section{INTRODUCTION}

"Critical Analysis of Architecture and its Context" is an architectural theory class for the third-year students of the School of Architecture, University Tec de Monterrey, Campus Puebla in Mexico. The course's syllabus is structured around a European oriented approach to theory requiring the study of seminal philosophical texts that provide an overview of general spatial concepts and ideas. Nonetheless, a quick look at the suggested readings suffices to show that the content is not pertinent for a critical analysis of architecture and its intriguing contemporary Mexican context. Readings varying from Plato's Republic (380BC), to René Descartes' Discourse on the Method (1637), Jacques Derrida's Of Grammatology (1967) and Michel Foucault's The Archeology of Knowledge (1969) touch undoubtedly on fascinating theoretical and spatial topics, but remain disconnected from the rest of the School's curriculum and most importantly the vibrant everyday life of the city of Puebla outside the classroom.

My position as a visiting professor in the School of Architecture in 2015-2016 required me to teach the given course in English, but came with the option to redefine the syllabus, propose a different reading list, suggest assignments for the students to engage with the material, and reconsider what the examination could be. Although this freedom seemed to stem from a concern that the students' proficiency in English would not allow for the study of philosophy and the writing of a paper, it slowly became clear that Mexican professors who had also taught the class in the past-and actually in Spanish-had found the suggested reading list to be particularly dense and a bit out of place for the needs of the students. Being out of place myself, a foreigner teaching in a new context, I decided to shift my focus onto this very context and examine with the students its architectural and urban characteristics from a theoretical perspective. My pedagogical agenda was already biased by my very own travelling in Mexico the very previous years. I wanted to challenge the students, and future young architects to develop a critical capacity and take an ethical stance in a place where unfortunately issues of social inequality, political injustice, loss of cultural identity and character were clearly and sadly reflected on the built environment.

\section{THE CONTEXT}

Puebla-also known as Puebla de los Angeles-was founded in 1531 as a Spanish settlement between Mexico City and the port of Veracruz. It's historic center, ordered systematically on a perfect rectangular grid, bursts with impressive Renaissance and Baroque buildings ${ }^{1}$ many of which are currently left deserted and unfortunately decay. Within this unique urban setting with the clear European influences, a number of lively activities transpire on a daily basis. Apart from the many offices and commercial stores, countless street-vendors populate the sidewalks selling food and everyday items. Doors of old colonial houses open up inviting people into tiny impromptu restaurants in the half-hidden courtyards beyond. Squares are filled with jesters, clowns, musicians, and on many occasions carousels and amusement rides.

A few kilometers outside the center this colorful urban vividness fades rapidly away. The urban sprawl is dominated by a proliferation of gated residential communities, the wellknown fraccionamientos. ${ }^{2}$ Varying in size, character, quality of construction and amenities these bubbles of domestic life exist inside protective walls outfitted with wire mesh and surveillance equipment. Security guards stand at the entrances controlling the coming and going of people. Gates open and close following their command. Everything is designed to offer the illusion of protection from crime, robbery or abduction, in a country that everyday security is not a given. In this part of the city, large malls, huge commercial buildings and "life-style centers" with bars, restaurants and cinemas-with many American chains among them-offer high-end retailing amenities and entertainment options for the residents of the gated communities. To this reality, local and international architects add landmark buildings which are abruptly disconnected from the cultural and environmental possibilities of Puebla; with Toyo Ito's International Baroque Museum in 2016 being one of the most characteristic examples.

And then a few kilometers further away, the mesmerizing Mexican landscape takes over, seeded literally with countless small and flimsy concrete-block structures among cacti and maize. These simple structures, many times built with just concrete blocks, form small or bigger communities and 
villages. They are built by their owners and hardly provide for the basic everyday needs of the extended families which usually reside in them. This multifaceted and uneven reality-to which my brief description can hardly do justice-is not unique to Puebla, but rather particularly Mexican, as my own travelling through the country had already revealed and as colleagues and local architects confirmed for me. It was the reality my very own students would face in the years to come, and for which they did not seem prepared, either because they were not fully aware of it or because it was so embedded in their everyday habitual lives that they could not properly see it.

Moreover, this fascinating context was interestingly represented in the demographics of the University's student population. Tec de Monterrey, although a private university with high tuition, is paradigmatically committed in providing educational opportunities to students from as many diverse social strata as possible. Almost fifty percent of its student population studies on scholarships or reduced tuition fees. As a result, the classes are shaped by a unique amalgam of students from distinctively different backgrounds. Their coexistence in the same classroom provided the context for insightful and heated conversations during the semester.

\section{THE COURSE}

With the opportunity to work with such a diverse mix of students and given my interest in developing their capacity for ethical judgment and action in the near future, it seemed imperative to me to turn their focus on their immediate context. To attain this pedagogical goal, I decided to anchor the class around a balanced combination of contemporary theoretical readings, both by Mexican and international thinkers, as well as Mexican literary readings that portray everyday urban characteristics familiar to the students. From my own research I was well aware that literature can shed light and facilitate discussions on theoretical questions through the engaging and often easier-received means of narrative. ${ }^{3}$ । paired these readings with assignments that could further provoke critical thinking and ethical decisions and I took the opportunity to suggest a design project, in place of the more conventional paper-writing, for the final exam of the semester.

The course started with an examination of seminal philosophical essays on issues related to place and architecture. Following a path informed by phenomenological hermeneutics, we looked into Edward Casey's discourse on place, Hubert Dreyfus suggestion's on atmospheres, Juhani Pallasmaa's understanding of the body in place, Octavio Paz's analysis of well-known Mexican social phenomena and buildings, Luis Barragan's short writings on the modern way of living in Mexico and the loss of Mexican identity, Mauricio Roza's manifestoes on architecture and local identity, among others. From literature we studied works in which space and architecture are the most important characters in the narratives. We looked into Gonzalo Celorio's And let the Earth Tremble at its Centers (1990), which portrays exceptionally the discrepancies between the colonial architectural context and the everyday Mexican reality. We read short stories by Juan García Ponce like "The coffee place" (2002) and "The cat" (1974) which capture changing atmospheres of the urban environment through everyday life activities, and we explored the renowned masterpiece Pedro Paramo (1955) by Juan Rulfo which depicts the built context of the Mexican countryside poetically weaving in its plot the customs, beliefs and prejudices particular to the culture. The importance of a place's atmosphere and character for architecture, the value of identity and culture for the built environment, the sociopolitical conditions that influence the development of our urban places, the strong ties between language and place emerged through these readings and our weekly conversations.

Alongside with the readings the students were asked to work with videos, sound recording, models and short texts in order to grasp and further study the particular concepts through real life situations grafted upon the given urban context of Puebla. They tried to identify the elements that capture the atmosphere of a place through short videos; they attempted to record the changes over time a place goes through via photographs and sound recordings; they ventured to understand how political conditions and legislations have an impact on architecture by looking into laws and policies. Each week, they submitted a short piece of critical writing: their own response to specific questions and topics we would discuss in class. Kate Nesbitt's definition of critical theory was a valuable guide in this process, helping students appreciate the power of this kind of writing: "...Critical theory evaluates the built world and its relationships to the society it serves. This kind of polemical writing often has an expressed political or ethical orientation and intends to stimulate change." 4

\section{WORDS IN PLACE}

With this preparation in place the students started working on the final assignment of the semester: the project "Words in Place." They were asked to choose one of the urban and architectural problems they had already identified in the city and develop a clear architectural critical message addressing it. Their message was meant to raise awareness by pointing at the architects' and the authorities' ethical responsibility and it was meant to address an audience much larger than that of the classroom. It had to be actually written on a surface or installed in a place in the city, in a scale appropriate for the urban environment. In short the students had to design that very writing and execute it in a 1:1 scale in Puebla. To this end they had to contemplate the limitations of their own making, adjust their design in view of particular technical constrains or overcome them, and think about their installations in order to correspond to environmental and social conditions. The content of the message, its writing in a carefully chosen location, 


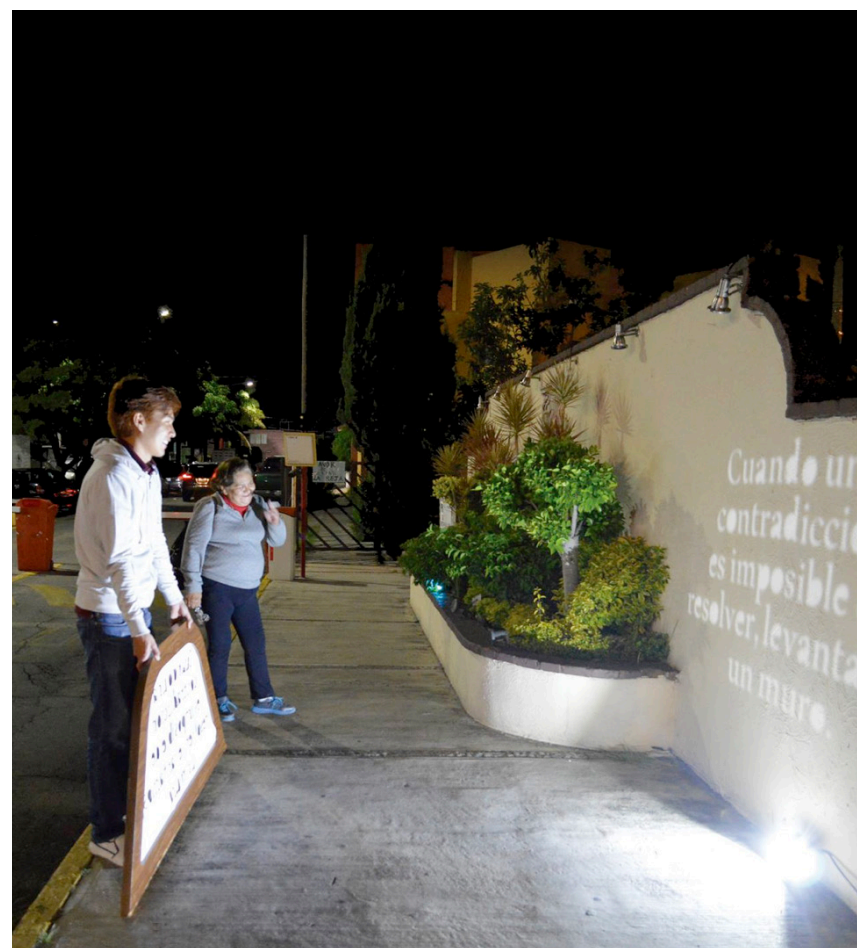

Figure 1: "Reflecting on Walls," 2016. (Project by the students Amauri Pacheco García, Cesar Uscanga, Karla Julissa Velázquez Espina)

and the medium of the writing had all to work creatively and appropriately together to make the students' message be heard loud and clear. Given that this project was conceived as part of a theory class and not a design studio, the objective was not to provide an answer to the architectural criticism through a design proposal. The focus was strictly on rigorously shaping and provocatively writing the criticism itself, after developing a clear ethical stance on a specific issue. ${ }^{5}$

Through desk-crits and constant iterations of their ideas, the students reached the point that the message was ready to be written or installed in place. The full creation of their writing/installation in situ was an important reminder that any architectural intervention gets materialized in a lived place already embedded with meaning, a place that bears its own characteristics, qualities and atmospheres and constitutes a most significant element of the architectural outcome. Moreover, given that the students had to actively create the writing at the given place, the majority of the projects had a performative element; that of the students actually working in situ and bringing their project to life by negotiating the encountered place-specific conditions. This performative part of the assignment was something we discussed extensively, as it bears affinities with an approach to architecture which values the role of the architect beyond a mere form maker in front of a screen and engages them in the process as part of a bigger community in which their work is addressed. With the aid of the Mexican theoretician Alberto PérezGómez and his essay "Architecture as a Performing Art: Two
Analogical Reflections" we contemplated the idea that "if one may dream of an architecture capable of revealing to others a meaningful world (...) one must reconsider the origins of architecture as the space of participatory performance." ${ }^{\prime}$ Indeed "prior to the nineteenth century it was a common understanding that the work and ethical responsibility of an architect should be kindred to 'performance,' including the 'actualization' of buildings, gardens, ephemeral structures, fireworks, etc.-all seen as works of architecture insofar they offered the possibility of cultural orientation."7 With such an emphasis on the performative character of architecture and through their critical messages, the majority of the students ended up creating writings in places that challenged the common urban assumptions and practices in Puebla and questioned the architectural possibilities of the Mexican culture for the future.

\section{THE EXAMPLES}

"Vivienda Digna" is one of the most characteristic examples of the students' work and thus I would like to discuss it in detail. I will then provide shorter descriptions for two more projects. "Vivienda Digna" critiqued the lack of appropriate social housing programs for the region of Puebla. The students produced an installation made with concrete blocks sited in the city's Town Hall Square. It particularly targeted the paradoxical and impractical nature of a housing program addressed to the poor rural population of the state that was developed by the governor in power at the time. The name of the housing program itself was "Vivienda Digna," which can be translated as dignified housing. The government's stated intention was to promote an orderly and sustainable development in the area, improving and regulating the urban as well as the rural living. The expectation was to offer at the local families an actual access to a housing solution that would allow them to exercise their constitutional right for a life with dignity. ${ }^{8}$ The program was supposed to offer to the eligible families (criteria of eligibility based on their annual income) a number of concrete blocks and written instruction on how to construct a space of approximately twenty-five (25) square meters on land they owned. For the families to subscribe to the program they had to fill in a considerable number of forms, some of which are quite complicated.

The students first of all noticed that the majority of the people who were eligible to apply at this program were illiterate, so the process of filling in the forms or reading the instructions was already a challenge. Moreover, they noted that the program would provide nothing more than the concrete blocks and there was no provision for roof-materials. As a reaction to this parody they decided to create an architectural critical message in the form of ironic rules, satirizing the inefficiency of the political authorities and the indifference of the local architectural community. Their precedent was the work of the Argentinian writer Julio Cortazar. His celebrated "Instruction Manual," a collection of short pieces 


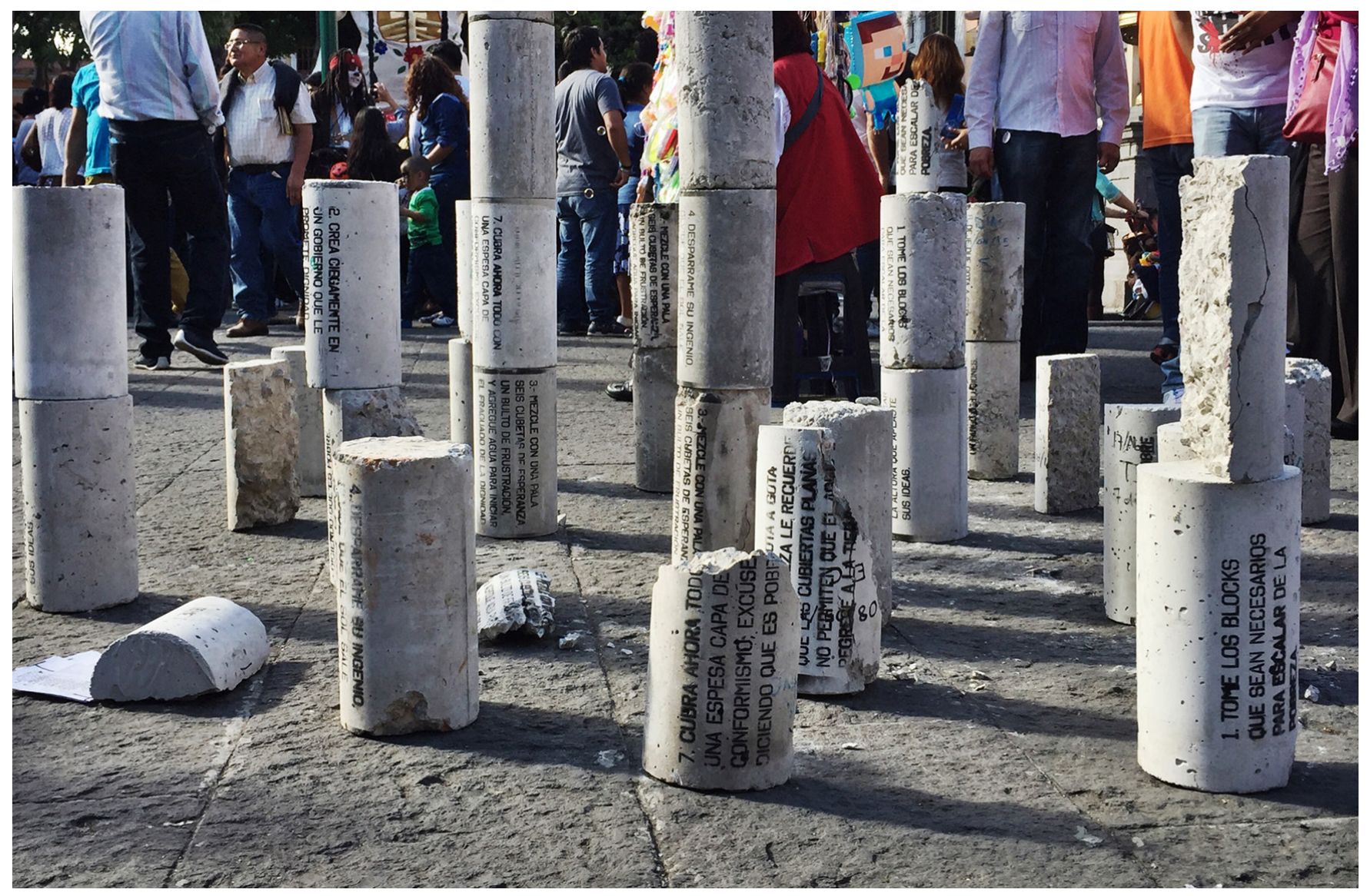

Figure 2: "Vivienda Digna," 2016. (Project by the students Aracely Baca Carmona, Kenya Bahena, Rubén Olvera Meneses)

offering unnecessary, poetic or even surreal instructions on how to perform everyday simple tasks like crying or climbing a staircase, served as a guide. ${ }^{9}$ The students' message took the following form:

1. Take as many concrete blocks as you need to climb out of poverty

\section{Believe blindly in a government that promises you dignity}

3. Mix with a shovel six buckets of hope, a package of frustration and the necessary water and allow for dignity to start setting.

4. Suppress your ingenuity and forget that the sun rises from the east and sets in the west.

\section{Cement everything under a mud of illusions.}

6. Place the blocks on top of each other until you reach the height that crushes all your ideas and dreams.

7. Cover everything with a thick layer of conformism with the excuse that you are poor.
8. And then let nature remind you drop by drop that flat roofs do not allow water to return to the earth. ${ }^{10}$

The students decided to install this message in front of Puebla's Town Hall where people are required to go in order to complete the required forms. This is also where the city's main central square is located. Given the program's use of concrete blocks, they also thought it appropriate to find a way to incorporate concrete in their installation. They looked for defective cylindrical concrete specimens; the ones used for testing the strength of the material. With the use of reusable stencils, that they created, and black spray paint they wrote each one of the instructions on many different cylinders. Afterwards, they carried their concrete blocks to the main square in front of the Town Hall on a busy afternoon. In the middle of a lively chaos they started building a ruinlike structure, creating a number of short columns by slowly placing the concrete cylinders on top of each other. The final outcome was meant to give the impression of an unfinished structure; of something that looked more like the skeleton of a structure than a complete structure in itself. Given that the day the students chose to install their message in the square coincided with the celebrations for the important Mexican tradition "The Day of the Dead," this skeleton-like structure seemed in perfect dialogue with the many humanskeletons present in the square. ${ }^{11}$ (Figure 2) Putting together the installation lasted for almost an hour as the students 


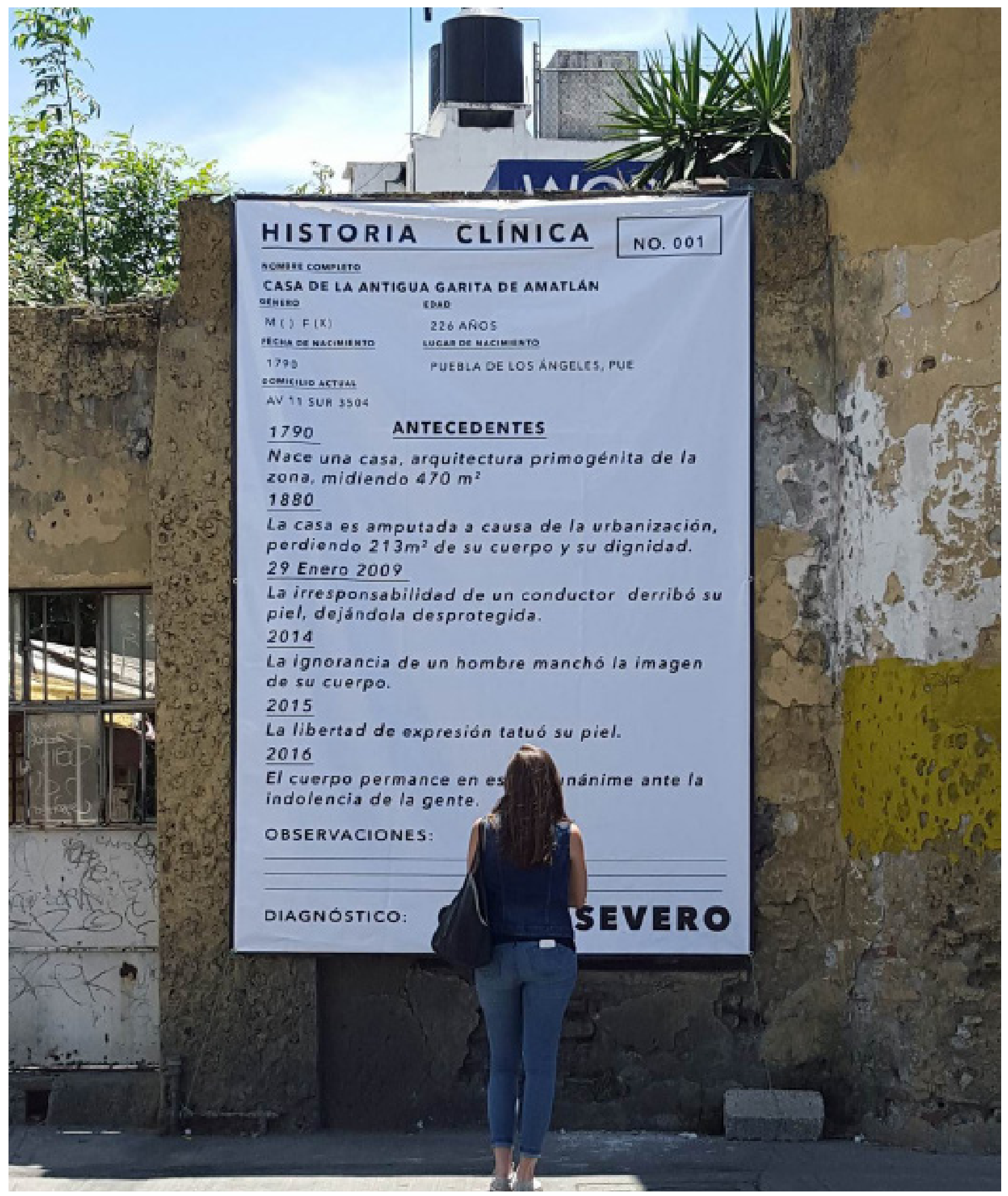

Figure 3: "Severe Coma," 2016. (Project by the students Florencia Arias Richaud, Ilan Rojas Solano, Mario Fermin Martinez Miguel) 
slowly claimed more and more of the square's public surface. The city inhabitants and the tourists were discreetly walking around them in the beginning, but as the structure acquired its final form many of them were stopping to read and ask questions. The students were handing them a small piece of paper containing the surreal instructions in the proper order from one to eight, explaining further the intention of their installation. The writing remained in place for two hours until local policemen arrived and asked the students to disassemble everything and vacate the square immediately.

In a similar provocative and interactive way, "Reflecting on Walls" was a performance that took place in front of numerous fraccionamientos of Puebla. Inspired by philosopher Simone Weil the students' message was: "When a contradiction is impossible to resolve, we build a wall." Installed as a negative and in reverse on a mirror, the students managed to create a reflection of their message on the walls of the fraccionamientos by projecting light on the mirror itself. (Figure 1) This method was meant to provoke the dwellers of these places reflect on their chosen way of living and how they are damaging any possibility of coexistence in the city. Many people talked to the students while they were standing outside the fraccionamientos and listened to them as well, as they tried to communicate their opinion on the role of architecture in society.

On the other hand, "Severe Coma" was interested in raising people's awareness on the rich architectural heritage of the city that daily falls apart. The novel Pedro Paramo (famously depicting a village falling in ruins) was a seminal influence on their work. They chose to work with the oldest building of Puebla-almost completely abandoned now. They studied its history and conceived of it as a medical chart of a patient under coma. Neither living nor dying either the building was for the students a patient in eternal coma and the medical chart they created, was printed in a scale as high as the building's facade, installed on it for a week, inviting passersby to leave comments and interact with the installation. (Figure 3)

\section{CONCLUSION}

Through their work the students ended up creating new temporary places in the places where they worked. All the projects questioned architectural and urban norms in Puebla and opened up possibilities for dialogue in the local community. Seen as explorations of Hannah Arendt's "space of appearance," this short-lived spaces of dialogue and participation which emerged prompted political consciousness and critical architectural thinking. As Arendt herself points out this space of appearance may be "fragile"-failing to survive the actuality of the movement that brings it into being and disappearing with the dispersal of men and the arrest of the activities themselves-but by emerging even for a short time-period has the potential to express political or ethical concerns and stimulate change. ${ }^{12}$ Students realized their own ethical stance, their very ethical responsibility, the political implications of their interventions and the power of architecture. In the case of the "Severe Coma" a local journalist actually approached the students and invited them at the local radio station to talk about their work, explain their position, elaborate on their ideas as future architects. This way their words managed to travel beyond the specific place. Other projects as well caught the attention of a wider public, which prompted us to submit a proposal at the local museum and set up an exhibition of all the different critical writings. Local journalists were invited at the press conference organized by the museum before the official opening and the students' work started appearing in Puebla's newspaper, blogs and radio stations. It was an outcome they had not envisioned and which showed them tangibly that architects may truly contribute to society: their acts and deeds constitute an appropriate praxis, a political position driven by ethical concerns. Moreover, it offered them a deep appreciation for the importance of philosophical orientation in their education. They highly valorized studying a theory of the discipline that demonstrates, through example, how architecture strives to respond to the fundamental questions of being human in different times and places. "Words in place," allowed them to approach theoretical questions, understand architectural design as ethical response, and see the city as a surface of possibilities they had never imagined before.

\section{ENDNOTES}

1 The center of the city was declared an International Unesco monument in 1987 (http://whc.unesco.org/en/statesparties/mx)

2 Puebla, the capital of the state with the same name, has an exceptionally large number of fraccionamientos compared with other cities in the country.

3 In Reason in The Age of Science, Hans-Georg Gadamer argues that what has traditionally been the role of philosophy, meaning the study of the fundamental nature of knowledge, reality, and existence, has in recent centuries been undertaken by literature. "The great novels of the nineteenth and twentieth century are closer to the old tasks of philosophy and we should look upon them as the custodians of philosophy's great heritage." Hans-George Gadamer Reason in the Age of Science, trans. Frederick G. Lawrence (Cambridge; MA: MIT Press, 1981), 146.

4 Kate Nesbitt, ed., Theorizing a New Agenda for Architecture; An Anthology of Architectural Theory 1965-1995 (New York: Princeton Architectural Press, 1988), 18.

5 Although the course was taught English the final architectural messages were written in Spanish. English is not a language widely spoken in Puebla and allowing for the message to be written in Spanish was the only way to make it accessible to the larger audience the project intended to address.

6 Alberto Pérez-Gómez, "Architecture as a Performing Art: Two Analogica Reflections," in Timely Meditations; Selected Essays on Architecture, v. 2 (Montreal: RightAngle International, 2016), p. 80

7 Ibid., p. 88

8 "Programa Vivienda Digna," Official Website of the Mexican Government, accessed April 2017, https://www.gob.mx/fonhapo/acciones-y-programas/ programa-vivienda-digna. Translation by the author.

9 "The Instructions Manual" is the first chapter of Julio Cortazar's book Cronopios and Famas published in 1962.

10 The message was created by the students Aracely Baca, Kenya Bahena and Rubén Olvera.

11 For the "Day of the Dead" Mexicans get dressed up like skeletons or carry around catrinas, which are female skeletons with actual clothes. For more see: Lemnitz, Claudio, Death and the Idea of Mexico (Brooklyn, NY: Zone Book), 2005.

12 Hannah Arendt, The Human Condition, (Chicago; London: The University of Chicago Press, 1958), 199. 